\title{
Time heals everything
}

David Croser

Dento-Legal Adviser, Dental Protection Ltd

Is it true that time heals everything? Certainly not when it comes to debt repayment. Compounded interest on credit cards causes the total of the unpaid debt to worsen alarmingly rather than to improve. Whilst the festive season may not be the best time to mention this, the situation can be even worse if you have recently lost your job. Unfortunately this is exactly what has happened to at least half a dozen UK oral healthcare workers this year. Their ability to work normally in general practice was removed because they had been diagnosed as HIV positive $(\mathrm{OHCW}+)$.

The guidance from the UK Advisory Panel for Healthcare Workers Infected with Blood-borne Viruses (UKAP) was originally introduced as a precautionary measure in the 1990s when healthcare in the UK and around the world was subjected to significant levels of scrutiny. The need for precautions in dentistry was decided by this small advisory body in the light of the David Acer case, in which the reason for six patients apparently catching HIV from the same Florida dentist was never satisfactorily explained. ${ }^{1}$ As a result, oral healthcare workers with HIV were excluded from performing exposureprone treatment. The letters column of this edition of the $B D J$ contains a letter giving a detailed account of the awful reality of these restrictions (page 591).

\section{NO DOCUMENTED EVIDENCE OF HIV TRANSMISSION}

The evidence-base surrounding the transmission of HIV in a dental setting does not support the need for any such precautions. With the exception of the mysterious case of Dr Acer, there is no documented evidence anywhere in the world of transmission of HIV from a dentist to patient. Meanwhile, with the introduction of highly active anti-retroviral therapy (HAART, which can make the viral load undetectable in patients with HIV) and the universal application of high levels of infection control in dentistry (destined to move to even higher levels with the introduction of HTM 01-05), the possibility of such transmission recedes even further into the realms of the theoretical.

When the $B D J$ published an editorial ${ }^{2}$ and an opinion piece ${ }^{3}$ on this subject in October 2006 it was heartening to receive a letter from the Chief Dental Officer the following year (July 2007) which stated:

'I understand that the UK Advisory Panel for Healthcare Workers Infected with Blood-borne Viruses (UKAP), the Expert Advisory Group on AIDS (EAGA) and the Advisory Group on Hepatitis (AGH) have recently decided to review current policies on healthcare workers infected with blood-borne viruses. When that review is complete the committees will then make recommendations to the Chief Medical Officers of the health departments of England, Wales, Scotland and Northern Ireland. The first meeting of the tripartite working group is due to take place in the autumn.'

It is now more than four years since that editorial and no tangible action has been taken to eliminate the unnecessary sacrifice of all the dental careers that have been destroyed as the passage of time results in the deskilling of the individuals involved.

The publication of the consensus document (the Beijing Declaration $)^{4}$ in 2009 caused the GDC to recognise that they were vulnerable to being accused of discrimination if they were asked to consider a case of an OHCW+ who performed exposure-prone procedures in their practice of dentistry. But still there has been no change. Indeed indications from the Department of Health suggest that even though America, Australia and half of Europe have already modified their restrictions, the UK would not be able to effect any change in the regulations before the end of 2011 at the earliest - a further opportunity for the $\mathrm{OHCW}+$ to lose confidence in their professional skills.

The dreadfully slow response by the tripartite review is completely disproportionate to the speed with which the precautionary measures were introduced two decades ago. The original work of a small advisory body now requires a whole government department, a trio of advisory teams and a regulatory body to unpick the original decision.

In an attempt to focus the attention of the Department of Health on the continuing plight of $\mathrm{OHCW}+\mathrm{s}$, Dental Protection (DPL) has started a legal challenge which could see the present situation becoming the subject of a judicial review. Recently the Chief Executive of the BDA reinforced that challenge when he stated, 'There is no evidence-base for preventing dentists who are diagnosed as being HIV-positive from practising, and we believe it is unfair and unlawful. ${ }^{5}$

The whole profession is increasingly determined that the disproportionate penalty that is currently being paid by a few colleagues should cease. This is no longer a case of time heals everything - we are saying 'Time, ladies and gentlemen, please!'

1. Centers for Disease Control (CDC). Update: transmission of HIV infection during invasive dental procedures - Florida. MMWR Morb Mortal Wkly Rep 1991; 40(23): 377-381.

2. Hancocks S. Losing your livelihood just twenty minutes from now. Br Dent 2006; 201: 485.

3. Croser D. Written off. Br Dent J 2006; 201: 497-499.

4. The Beijing declaration 2009. http://www.hivdent.org/_nternational/2009/ BEIJING_DECLARATION_2009.htm (accessed 1 December 2010).

5. Anon. Call to overturn HIV rule. BDA News 2010; November: 3. 